\title{
Spatial Distribution Analysis of Community Radio Stations For Promoting Climate Change Adaptation Measures in Agriculture Under COVID-19 Scenario, Southern Province, Zambia
}

\author{
Albert Somanje ( $\square$ nsomanje@gmail.com ) \\ Ministry of Agriculture, Zambia Agriculture Research Institute (ZARI), Mochipapa Regional Research \\ Station, P. O. Box 630090, Choma.

\section{Lauraine Mwansa} \\ Ministry of Agriculture, Department of Agriculture, Lusumpuko House, P.O. Box 630042, Choma \\ Kafula Chisanga \\ Ministry of Agriculture, Zambia Agriculture Research Institute (ZARI), Mochipapa Regional Research \\ Station, P. O. Box 630090, Choma.
}

\section{Research Article}

Keywords: Agriculture, Climate adaptation, Community radio stations, COVID-19, Zambia

Posted Date: December 17th, 2021

DOI: https://doi.org/10.21203/rs.3.rs-1147966/v1

License: (c) (1) This work is licensed under a Creative Commons Attribution 4.0 International License. Read Full License 


\section{Abstract}

Community Radio Stations (CRS) play an important role in information dissemination at local and context specific levels. This study analyzes the spatial distribution of the CRS and their role in promoting sustainable in agriculture in times of Coronavirus Disease (COVID-19). The study's methodological approach included geospatial mapping of CRS in Arc GIS 10.3, surveys and interviews with key informants $(n=39)$. In addition, the data was analyzed using SPSS 28.0 for frequency and descriptive analysis and excel for graphical outputs. The study finds 19 CRS in 13 districts and their radii completely cover the Southern Province of Zambia. Out of the time allocated to agricultural programs, an average of $47 \%$ is on climate change adaptation measures in local languages. However, the CRS have limited access to experts to provide information and programs sponsorship. This study has established that CRS have potential in disseminating climate change adaptation measures. Sixty-nine percent (69\%) of the CRS noticed an increase in demand for agricultural programs during the COVID-19 era, with the rapid growth of CRS. The study recommends stakeholders collaboration to provide appropriate information to enhance the climate agricultural programmes on CRS and address challenges of limited access to experts and associated costs.

\section{Introduction}

Promotion of climate change adaption measures in agriculture is vital in Southern Province of Zambia because the area is negatively affected by climate change and weather variability. The province is located in the country's driest part in the agro-ecological regions I and II, with frequent droughts and high temperatures ${ }^{1}$. The province has a subtropical climate. There are three distinct seasons: the hot and dry season from August to October, the wet season from November to April, and the cold and dry season from May to July. The annual minimum temperature ranges from 15 to 27 degrees Celsius while the maximum ranges from 27 to 32 degrees Celsius ${ }^{1,2}$.

The province falls under two agro-ecological zones. Region I, on the southern part, receives less than 800 $\mathrm{mm}$ of rainfall per year while Region II, on the northern part, receives $800-1000 \mathrm{~mm}$ of rainfall per year. Southern Province is prone to the effects of climate change and weather variability. Weather variability has been a significant challenge in agricultural production and productivity ${ }^{1,2}$.

The dissemination of information on climate change adaptation measures is significant for small-scale farmers to adapt as well as build resilience. The channels for disseminating agricultural information for climate change adaptation are many, and one such approach is the use of radio broadcasts, especially in rural areas ${ }^{3-5}$. For example, in an army worm radio campaign survey, radio listeners where more likely to adopt control practices than non-radio listeners ${ }^{6}$.

However, limited studies have mapped CRS in Zambia and focused on agricultural information on climate change adaptation and sustainable agricultural production in times of COVID-19 for enhanced social distancing ${ }^{7}$ limited government extension services and declining budgetary allocation ${ }^{8,9}$. COVID-19 
has been found to impact the provision of agricultural extension services ${ }^{10}$. Davis ${ }^{7}$ highlights the need to change how agricultural extension services are provided in times of COVID-19 to ensure the safety of both the extension officers and the farmers. Potential solutions strategies are required to minimize the compound risks due to climate change hazards in the COVID-19 scenario ${ }^{11,12}$. Other studies have recognized the importance of radio services in agricultural extension and adaptation to climate change ${ }^{13,14}$.

In their review of adaptation processes by farmers in decision making, Robert et al. ${ }^{15}$ propose continuous and sequential flexible planning based on the available new information towards anticipated changes to the environment. Thus, the adaptation process to climate change starts with access to information, and therefore CRS play a fundamental role $e^{16,17}$.

For adaptation to occur, farmers need to have access to information such as weather information for planning their agricultural season ${ }^{16-18}$. Farmers may also have information on appropriate crop varieties depending on the weather and climatic condition at the local level ${ }^{15-17}$. Access to smart climate agricultural information such as conservation agriculture [minimum tillage/crop residue retention, crop diversity/association and crop rotation] is also critical for adaptation in Zambia ${ }^{19}$. In addition, crop and livestock diversification information is key to climate change adaptation to ensure resilience to climaterelated shocks ${ }^{15-17}$.

Information dissemination of innovative approaches from research and extension must be managed, shared in simple and clear terms for small scale farmers understanding through different platforms, including $\mathrm{CRS}^{17}$, and will require stakeholder engagement and collaboration. However, many processes in agricultural extension and food systems have been impacted by COVID-19. The impact of COVID-19 has been through the disruption of the food system due to the pandemic control measures, increasing numbers of confirmed cases and deaths at the global, regional and country levels. According to the World Health Organisation ${ }^{20}$, more than 247.5 million confirmed cases of COVID-19 and above 5 million deaths occurred globally. In Africa, more than 6.2 million confirmed cases of COVID-19 and 150, 825 deaths regionally, while in Zambia, there have been 209, 760 confirmed cases of COVID-19 with 3, 611 deaths recorded. Therefore, in a COVID-19 scenario, agricultural extension and dissemination of climate change adaptation measures should be intensified through approaches that have low-risk to COVID-19 but a broader impact on the public.

This study's overall objective was to assess CRS' potential effectiveness in promoting climate change adaptation measures under COVID-19 conditions. The specific objectives were: (i) to map out all the CRS in the Southern Province of Zambia; (ii) to assess how much time is allocated to climate change and sustainable agricultural information dissemination out of the regular programming time; and (iii) to assess challenges in the dissemination of climate change adaptation and sustainable agricultural information on CRS. The authors hypothesize an increase in the use of CRS for agricultural information 
dissemination because of mass coverage and reduced contact with farmers due to COVID-19 under traditional extension services (farmer visits and meetings).

The study focused on CRS because access by households across the radio stations is the highest at $81.3 \%$ compared with $79.8 \%$ and $55.7 \%$ for public and commercial radio stations, respectively, according to Zambia Information and Communications Technology Authority [ZICTA] ${ }^{21}$. In addition, CRS have been critical for community engagement during the country lockdown ${ }^{3}$. For this study, community radio is defined as a radio station focusing on local coverage. Therefore, all radio stations with national coverage and public radio station are not included in this study.

This study examines the number of CRS, their coverage areas (heatmap), and the local languages used by all CRS in Zambia's Southern Province. Also mentioned are key gaps in enhancing the community radio station's role in climate change adaptation and sustainable agricultural information dissemination. This research is critical for policy intervention in achieving Sustainable Development Goals (SDGs); SDG 2 (Zero hunger), SDG 3 (good health and wellbeing), SGD 13 (climate action) and SGD 17 (partnerships) $^{22}$.

\section{Results}

\section{CRS geospatial mapping}

The results show that the minimum radius coverage for the community radio station is $70 \mathrm{Km}$ (Chikuni radio and Power FM) and maximum of $350 \mathrm{Km}$ (SKY FM) see Figure 1. The average radius of the CRS in Southern Province is $170.58 \mathrm{KM}$. The Sky FM in Monze district has the highest coverage area among the CRS and has an estimated 3,000,000 listeners, and Kabulamwanda Community Radio Station has the least number of 2,000 listeners (Figure 2). In addition, the average audience for all the CRS in Southern Province $(n=19)$ is estimated at 648,389 .

The majority $(78.9 \%)$ of the radio stations are privately managed, while $21.1 \%$ are managed by faithbased organizations $(n=19)$. Four of the thirteen districts have no community radio station (Gwembe, Pemba, Sinazongwe and Zimba). Choma and Livingstone districts have four community ration stations each, the highest number per district. An analysis of the heatmap for the spatial distribution of the CRS shows that they are more on the eastern half of the province than the western side of the Southern Province (Figure 3).

\section{Allocated time to climate adaptation measures programs on CRS}

Given the COVID-19 period, the demand for broadcasting agricultural-related programs increased in the majority of the CRS (69\%) as shown in Figure 4 . The average weekly estimated time (\%) allocated for 
agricultural programs out of the normal programming hours is $16.65 \%$. In comparison, the average estimated time (\%) allocated for climate adaptation programs out of the time allocated to agricultural programming is $47.32 \%$ (Table 1 ). In all the 19-CRS surveyed, the common languages used are English and Tonga (39.9\%), while the least used languages are Illa, Goba and Bemba (1.8\%) (Table 2). The most combination of languages used by CRS $(n=13)$ is Tonga, Lozi and English, accounting for $68.4 \%$ (Table $3)$.

Table 1

The estimated weekly time allocated to agricultural programs on CRS

\begin{tabular}{|lccccc|}
\hline Time allocation & N & Minimum & Maximum & Mean & $\begin{array}{l}\text { Std. } \\
\text { Deviation }\end{array}$ \\
\hline $\begin{array}{l}\text { Estimated time (\%) allocated for agricultural } \\
\text { programs }\end{array}$ & 19 & 1 & 60 & 16.65 & 18.830 \\
\hline $\begin{array}{l}\text { Estimated time (\%) allocated for climate } \\
\text { adaptation measures on agricultural }\end{array}$ & 19 & 0 & 100 & 47.32 & 33.771 \\
\hline \begin{tabular}{l} 
Source: Survey (2021) \\
\hline
\end{tabular} & & & & & \\
\hline
\end{tabular}

Table 2. The number of languages used in information dissemination by the CRS

\begin{tabular}{|c|c|c|c|}
\hline \multirow[b]{2}{*}{ Languages used (multiple response) } & \multicolumn{2}{|c|}{ Responses } & \multirow[b]{2}{*}{ Percent of Cases $(\%)$} \\
\hline & $\mathrm{N}$ & Percent $(\%)$ & \\
\hline English & 19 & 33.9 & 100.0 \\
\hline Tonga & 19 & 33.9 & 100.0 \\
\hline Lozi & 13 & 23.2 & 68.4 \\
\hline Illa & 1 & 1.8 & 5.3 \\
\hline Goba & 1 & 1.8 & 5.3 \\
\hline Bemba & 1 & 1.8 & 5.3 \\
\hline Nyanja & 2 & 3.6 & 10.5 \\
\hline Total & & 100.0 & 294.7 \\
\hline
\end{tabular}

Source: Survey (2021) 
Table 3

The available combinations of languages used and the number of the CRS

\begin{tabular}{|lllll|}
\hline Combination of Languages & $\begin{array}{l}\text { Number of } \\
\text { CRS }\end{array}$ & Percent & $\begin{array}{l}\text { Valid } \\
\text { Percent }\end{array}$ & $\begin{array}{l}\text { Cumulative } \\
\text { Percent }\end{array}$ \\
\hline Tonga and English & 3 & 15.8 & 15.8 & 15.8 \\
\hline Tonga, Lozi and English & 13 & 68.4 & 68.4 & 84.2 \\
\hline $\begin{array}{l}\text { Tonga, Lozi Nyanja, Bemba and } \\
\text { English }\end{array}$ & 1 & 5.3 & 5.3 & 89.5 \\
\hline Tonga, Goba, Nyanja and English & 1 & 5.3 & 5.3 & 94.7 \\
\hline Tonga Ila and English & 1 & 5.3 & 5.3 & 100.0 \\
\hline Total & 19 & 100.0 & 100.0 & \\
\hline Source: Survey (2021) & & & & \\
\hline
\end{tabular}

\section{Challenges and opportunities for CRS in promoting climate adaptation measures}

The major challenge faced by CRS (42.1\%) is the limited access to agricultural experts that would continuously feature and disseminate climate-smart agricultural information and techniques. However, the significant opportunities that CRS (36.8\%) in Southern Province have is proximity to farmers at the local level (Figure 5).

The high response (36.8\%) from CRS on being closer to farmers as an opportunity is also reflected in the distribution of CRS in 9 out of the 13 districts. In addition, an analysis of the trends in the registered and operating radio stations shows that there has been a steady increase in the number of radio stations, from two (2) to nineteen (19), from 2000 to 2021, respectively (Figure 6). The increase in the number of CRS also shows the effectiveness potential through coverage and diversity in information dissemination in most districts of Southern Province.

\section{Discussion}

The community radio station mapping results suggest that the entire Southern Province is covered as evidenced by the radius transmission coverage. This corroborates well with findings from the survey conducted in 2018 which showed that $83.1 \%$ of the households that own radio sets have access to the CRS in the country ${ }^{21}$. The heatmap has also revealed that CRS are more concentrated on the Eastern than the Western side of the Southern Province. The concentration of CRS on the Eastern side of the province could be attributed to population distribution, fairly developed infrastructure and terrain. 
The demand for agricultural programs from agricultural organisation and companies increased for $69 \%$ of the CRS during the COVID-19 period indicates that there is prospective effective information dissemination of agricultural information, including climate change adaptation measures in agriculture (SDG 2 and 13). In Southern Province of Zambia, the confirmed COVID-19 cases are 2, 900 and 116 deaths as at November $03,2021^{23}$. The vaccination rate for COVID-19 is still low in Africa $(0.6 \%)^{24}$, while in Zambia only 538,310 (2.9\% of the population) have been fully vaccinated as at November 1, $2021^{25}$ and CRS will continue to be essential in this COVID-19 scenario. The surge in demand for CRS were also observed in India for broadcasting services on COVID-19, news, health in a two-way communication approach ${ }^{3}$. Prahmana et al. ${ }^{4}$ findings also reveal that CRS plays' an essential role in ensuring blended learning models, especially in remote rural areas during the pandemic era. This approach is also essential in achieving good health and well-being (SGD 3) for extension experts and farmers in general ${ }^{26}$.

Although the demand for agricultural programs on CRS has increased during the COVID-19, there are still challenges. The major challenge identified in this study faced by the CRS is limited access to specialized experts to be available continuously throughout the year. During the interviews, it was also revealed that experts on climate adaptation measures are only available for a short period of time during the rainy season, in some cases it is too costly for CRS. Similarly, Abdulai et al. ${ }^{27}$ have shown that community engagement is essential for climate change knowledge transfer (SDG 13). Although these challenges exist, there are opportunities that can be maximized to enhance CRS dissemination of climate adaptation measures. This study identifies that proximity to farmers at the local level not only increases accessibility to climate adaptation information but also entails local ownership, participation, culture, and values that are context-specific for local adaptation to climate change in a COVID-19 scenario. Similar key drivers are appropriate for local-led adaptation initiatives suggested by Westoby et al. ${ }^{28}$.

This study demonstrated that geospatial analysis of CRS can methodologically contribute to the visual understanding of the potential effectiveness in disseminating climate change adaptation measures. The study also has made known the interlinkages of engagement of CRS in information dissemination and how this can contribute to achieving the SDGs at national, regional, continental and global levels.

\section{Conclusion And Recommendations}

This study has established that community radio stations have potential effectiveness in disseminating climate change adaptation measures in agriculture (SDG 2 and 13), as shown through the transmission coverage in Southern Province of Zambia. Sixty-nine percent (69\%) of the CRS noticed an increase in demand for agricultural programs during the COVID-19 era. On average, it is also estimated that $47 \%$ of the agricultural programming is allocated to climate change adaptation. Furthermore, all radio stations broadcast programs in local languages, which is critical for local context adaptation. The increase in CRS from two (2) in 2000 to nineteen (19) in 2021, is also a clear indication of the growth and potential in information dissemination and coverage (SDG9). 
The study recommends that Ministries of Agriculture (extension and research wings), Fisheries and Livestockand Green Economy and Environment should provide appropriate information on climate-smart agriculture to CRS to enhance the climate-smart agricultural radio programmes. Further, close partnerships with agricultural stakeholders and other corporate bodies to sponsor climate-smart agricultural radio programs are required, which is key to SDG 17. It is imperative to promote CRS in Gwembe, Pemba, Sinazongwe and Zimba districts for stakeholders willing to set up radio stations through the provision of radio licenses in these districts by ZICTA.

Lastly, studies that include farmers perception of CRS in the COVID-19 scenario through a mixed-methods approach and fully test the proposed theoretical framework can be done.

\section{Methods}

\section{Conceptual framework}

In order to address the objectives of this study, the authors propose a modified integrated framework for analyzing pluralistic agricultural extension performance through the effectiveness of information sources $^{29,30}$ and perceptions ${ }^{31,32}$ based on the innovation diffusion theory by Rogers ${ }^{33}$. In addition, the development of communication theories underscores the use of mass media such as $\mathrm{CRS}^{5}$. Information dissemination is the core mandate of agricultural extension services, innovation diffusion, and knowledge acquisition ${ }^{32-34}$ (Figure 7). Birner et al. ${ }^{29}$ and Swanson et al. ${ }^{35}$ define effectiveness as meeting the objective or target set to deliver quality agricultural services through regular interaction with farmers, such as raising awareness, in this context through CRS. For this paper, the study focuses on community radio operations and the potential effectiveness in dissemination of agricultural information under the COVI-19 scenario.

\section{Methodological framework}

This study employed a three methodological approach. Steps 1 and 2 address objective 1 using GIS mapping and spatial analysis. Step 3 addresses objectives 2 and 3 through administering questionnaires to the CRS and validating the information with officers from the Ministry of Agriculture (Figure 8).

\section{Study population and sample size}

This study was done in the Southern Province, Zambia. The province has 13 districts in which all the CRS available were included in the study (Figure 9). In addition to mapping the $\mathrm{CRS}^{36,37}$, nineteen (19) radio station staff were interviewed, and 20 agricultural officers validated community radio station information (Tables 4 and 5). Purposive sampling was employed for the key informants ${ }^{35,38-42}$ while a snowball technique was applied for agricultural officers $39,40,43-45$. 
Table 4

Community Radio Station Key Informants

\begin{tabular}{|lllll|}
\hline Position & Frequency & Percent & Male & Female \\
\hline Station Manager & 8 & 42.1 & 7 & 1 \\
\hline Programs Manager & 7 & 36.8 & 4 & 2 \\
\hline Marketing Manager & 3 & 15.8 & 2 & 1 \\
\hline Reporter & 1 & 5.3 & 1 & 0 \\
\hline Total & $\mathbf{1 9}$ & $\mathbf{1 0 0 . 0}$ & $\mathbf{1 5}$ & $\mathbf{4}$ \\
\hline
\end{tabular}

Table 5

The Ministry of Agriculture Key Informants

\begin{tabular}{|lllll|}
\hline Position & Frequency & Percent & Male & Female \\
\hline District Agricultural Information Officer & 12 & 60 & 6 & 6 \\
\hline Provincial Agricultural Information Officer & 1 & 5 & 1 & 0 \\
\hline Senior Agricultural Officer & 5 & 25 & 5 & 0 \\
\hline Agricultural Officer & 1 & 5 & 0 & 1 \\
\hline Program Officer (Agricultural Research) & 1 & 5 & 1 & 0 \\
\hline Total & $\mathbf{2 0}$ & $\mathbf{1 0 0 . 0}$ & $\mathbf{1 3}$ & $\mathbf{7}$ \\
\hline
\end{tabular}

\section{Study instruments, data collection and analysis}

To achieve objective 1, the authors applied Geographical Information System (GIS) mapping of all CRS and their coverage areas to create a heatmap ${ }^{36,37}$. The focus was on CRS because of their unique setting compared with national broadcasting stations. Climate change adaptation measures and sustainable agricultural production are easily adopted when scaled down and contextualized to the local situation. Most CRS understand the local context, social and cultural norms, and the local language, making them ideal for climate adaptation information dissemination ${ }^{28}$. The mapping was applied using the Global Positioning System (GPS) and ArcGIS 10.3 and Geospatial analysis of the available radio stations ${ }^{36,37}$. This study used the World Geodetic System (WGS84) as its reference coordinate system ${ }^{46}$.

The study used the android GPS test application to collect GPS coordinates for all the radio stations in Southern Province. The coordinates were validated using Google Maps ${ }^{47,48}$ to ensure the accuracy and precision of the radio station buildings. To address objectives 2 and 3 , the authors used survey questionnaires on CRS in Southern Province, Zambia and key informant interviews ( $n=19$, Tables 4$)$ and validated by informants from the Ministry of Agriculture $(n=20$, Tables 5$)$. Data from questionnaires was analysed using Statistical Package for the Social Sciences (SPSS). The results of this study are presented using spatial analysis figures, descriptive and frequency statistics. 


\section{Ethical approval and consent to participate}

The Ministry of Agriculture through the Zambia Agriculture Research Institute (ZARI) approved the research study. Furthermore, the authors obtained informed consent from each participant in the survey through a Yes/No before beginning the interview. All participants were informed about the context of the study and the anonymous nature of the survey. Permission was sought from each respondent, and they openly and freely answered the questions asked.

\section{Declarations}

Acknowledgements: We acknowledge the support from the Ministry of Agriculture staff in all the districts of Southern Province, Mr Lee Hantebe, Mr Nkamga Hantumbu and Lawrence Kabutu for their contribution to this study during data collection period.

Consent for publication: All authors have read and agreed to the published version of the manuscript.

Availability of data and materials: The data set for this study is available from the corresponding author on request.

\section{References}

1. Jain, S. An empirical economic assessment of impacts of climate change on agriculture in Zambia. Sustain Rural Urban Dev Team. 32 (2006).

2. Aregheore, E.M. Country Pasture/Forage Resource Profiles, Zambia. Fao. FAO. Available from: http://docplayer.net/44874777-Country-pasture-forage-resource-profiles-zambia-by-eroarome-martinaregheore.html (2009).

3. Laskar, K.A., Bhattacharyya, B. Community radio stations' production responses to COVID-19 pandemic in India. Media Asia. 48. 243-57 (2021).

4. Prahmana, RCl, Hartanto D, Kusumaningtyas DA, Ali RM, Muchlas. Community radio-based blended learning model: A promising learning model in remote area during pandemic era. Heliyon. 7. (2021).

5. Servaes, J., Malikhao, P. Development communication approaches in an international perspective. Commun Dev Soc Chang. 158-79. (2008).

6. Rware, H., Kansiime, M.K., Mugambi, I., Onyango, D., Tambo, J.A., Banda, C.M., et al. Is radio an effective method for delivering actionable information for responding to emerging pest threats? $\mathrm{A}$ case study of fall armyworm campaign in Zambia. CABI Agric Biosci<bi>.</bi> 2(1). https://doi.org/10.1186/s43170-021-00053-8 (2021).

7. Davis, K. Agricultural education and extension in a time of COVID. Agric Educ Ext. 26 237-238. Available from: https://www.tandfonline.com/doi/full/10.1080/1389224X.2020.1764224 (2020).

8. Benin, S., \& Yu B. Complying with the Maputo Declaration Target. Washington, DC, USA. Available from: http://ebrary.ifpri.org/cdm/ref/collection/p15738coll2/id/127946 (2013). 
9. ReSAKSS. Regional Strategic Analysis and Knowledge Support Systems. ReSAKSS. [cited 2021 Aug 8]. Available from: http://www.resakss.org (2018).

10. Sampson, S., Mazur, J., Israel, G., Galindo, S., Ward, C. Competing Roles and Expectations:

Preliminary Data from an Agricultural Extension Survey on COVID-19 Impacts. Agromedicine. 18. 16. Available from: https://www.tandfonline.com/doi/full/10.1080/1059924X.2020.1815619 (2020).

11. Joseph Fernando, A. How Africa Is Promoting Agricultural Innovations and Technologies amidst the COVID-19 Pandemic. Mol Plant. 13. 1345-6. Available from:

https://linkinghub.elsevier.com/retrieve/pii/S1674205220302598 (2020).

12. Phillips, C.A., Caldas, A., Cleetus, R., Dahl, K.A., Declet-Barreto, J., Licker, R., et al. Compound climate risks in the COVID-19 pandemic. Nat Clim Chang. 15. 586-8. Available from:

http://www.nature.com/articles/s41558-020-0804-2 (2020).

13. Blum, J.M.L. Investment requirements in extension to achieve zero hunger and adapt to climate change. Agric Sci Technol A. 4. 552-62. (2014).

14. Drechsel, P., Zimmermann, U. Factors influencing the intensification of farming systems and soilnutrient management in the rural-urban continuum of SW Ghana. Plant Nutr Soil Sci.168. 694-702. (2005).

15. Robert, M., Thomas, A., Bergez J-E. Processes of adaptation in farm decision-making models. A review. Agron Sustain Dev. 4. 64. Available from: http://link.springer.com/10.1007/s13593-016-0402$\mathrm{x}(2016)$.

16. Ageyo, J., Muchunku, I.G. Beyond the Right of Access: A Critique of the Legalist Approach to Dissemination of Climate Change Information in Kenya. Sustainability. 12. 2530. Available from: https://www.mdpi.com/2071-1050/12/6/2530 (2020).

17. Kapinga, M.D., Siyao, P.O., Sife, A.S. Role of Community Broadcast Media in the Dissemination Of Climate Change Information among Small-Holder Farmers in Isimani Division, Iringa Rural District. Manag Dev Dyn.30.1-37. (2020).

18. Somanje, A.N., Mohan, G., Saito, O. Evaluating farmers' perception toward the effectiveness of agricultural extension services in Ghana and Zambia. Agric Food Secur. 10.53. Available from: https://agricultureandfoodsecurity.biomedcentral.com/articles/10.1186/s40066-021-00325-6 (2021).

19. Somanje, A.N., Crespo, O., Zinyengere, N. Conservation Agriculture Among Farmers in Kalomo, Zambia. In: Beyond Agricultural Impacts. Elsevier. 77-99. Available from: https://linkinghub.elsevier.com/retrieve/pii/B9780128126240000053 (2017).

20. WHO. WHO Coronavirus Disease (COVID-19) Dashboard I WHO Coronavirus Disease (COVID-19) Dashboard. [cited 2021 Nov 4]. Available from: https://covid19.who.int/ (2021).

21. ZICTA. 2018 National Survey on Access and Usage of ICTs by Households and Individuals. A Demand Side Assessment of Access and Usage of ICTs in Zambia. Lusaka Zambia: Zambia Information and Communications Technology Authority (ZICTA).1-33. (2018). 
22. Somanje, A.N., Mohan, G., Lopes, J., Mensah, A., Gordon, C., Zhou, X., et al. Challenges and Potential Solutions for Sustainable Urban-Rural Linkages in a Ghanaian Context. Sustainability. 12. 507. Available from: https://www.mdpi.com/2071-1050/12/2/507 (2020).

23. Ministry of Health. Zambia (COVID-19) General Dashboard. [cited 2021 Nov 4]. Available from: https://rtc-planning.maps.arcgis.com/apps/dashboards/3b3a01c1d8444932ba075fb44b119b63 (2021).

24. Cihan, P. Forecasting fully vaccinated people against COVID-19 and examining future vaccination rate for herd immunity in the US, Asia, Europe, Africa, South America, and the World. App/ Soft Comput.111. (2021).

25. Mathieu, E., Ritchie, H., Ortiz-Ospina, E., et al. A global database of COVID-19 vaccinations. Nat Hum Behav. [cited 2021 Nov 8]. Available from: https://ourworldindata.org/covid-vaccinations? country=ZMB (2021).

26. Yusha'u, M.J., Servaes, J. Communication for Sustainable Development in the Age of COVID-19. In: The Palgrave Handbook of International Communication and Sustainable Development. 3-30. (2021).

27. Abdulai. A-R., Chireh, V.K., Tchoukaleyska, R. Engaging Diverse Audiences: The Role of Community Radio in Rural Climate Change Knowledge Translation. Community Engagem Scholarsh.13. Available from: https://digitalcommons.northgeorgia.edu/jces/vol13/iss3/8 (2021).

28. Westoby, R., Clissold, R., McNamara, K.E., Ahmed, I., Resurrección, B.P., Fernando, N., et al. Locally led adaptation: drivers for appropriate grassroots initiatives. Local Environ. 26. 313-9. (2021).

29. Birner, R., Davis, K., Pender, J., Nkonya, E., Anandajayasekeram, P., Ekboir, J., et al. From Best Practice to Best Fit: A Framework for Designing and Analyzing Pluralistic Agricultural Advisory Services Worldwide. Agric Educ Ext.15. 341-55. Available from: http://www.tandfonline.com/doi/abs/10.1080/13892240903309595 (2009).

30. Ragasa, C., Ulimwengu, J., Randriamamonjy, J., Badibanga, T. Factors Affecting Performance of Agricultural Extension: Evidence from Democratic Republic of Congo. Agric Educ Ext. 22. (2016).

31. Elias, A., Nohmi, M. Yasunobu, K., Ishida, A. Farmers' satisfaction with agricultural extension service and its influencing factors: A case study in north west Ethiopia. Agric Sci Technol. 18. 39-53. (2016).

32. Ntshangase, N.L., Muroyiwa, B., Sibanda, M. Farmers' Perceptions and Factors Influencing the Adoption of No-Till Conservation Agriculture by Small-Scale Farmers in Zashuke, KwaZulu-Natal Province. Sustainability. 10. 555. Available from: http://www.mdpi.com/2071-1050/10/2/555 (2018).

33. Rogers, E.M. Diffusion of Innovations. 5th ed. Washington, DC, USA: Free Press (2003).

34. Adesina, A. Technology characteristics, farmers' perceptions and adoption decisions: A Tobit model application in Sierra Leone. Agric Econ. 9. 297-311. Available from: http://doi.wiley.com/10.1016/0169-5150(93)90019-9 (1993).

35. Swanson, B.E., Bentz, R.P., Sofranko, A.J. Improving agricultural extension. A reference manual. FAO. Rome: FAO. 303. (1997). 
36. Bekele, N., Demissie, B. Analyzing and Modeling of Geo Spatial Effect on Radio Wave Propagation System Using Geospatial Technologies. Geogr Inf Syst. 09. 777-95. Available from: http://www.scirp.org/journal/doi.aspx?DOl=10.4236/jgis.2017.96048 (2017).

37. De Smith, M.J., Goodchild, M.F. Geospatial AnalysisA Comprehensive Guide to PrinciplesTechniques and Software Tools. Sixth Edit. Troubador publishing Itd. 1-60. (2018).

38. Abunga, M., Emelia, G., Samuel, D. Adoption of modern agricultural production technologies by farm households in Ghana: What factors influence their decisions? Biol Agric Healthc. 2.1-14, (2012).

39. Cohen, L., Manion, L., Morrison, K. Research Methods in Education. Vol. 55, British Journal of Educational Studies. 254-263, (2007).

40. Creswell, J.W. Research Design: Qualitative, Quantitative and Mixed Approaches (3rd Edition). Research Design: Qualitative, Quantitative, and Mixed Methods Approaches. 1-295, (2009).

41. Maoba, S. Farmers' perception of agricultural extension service delivery in germiston region, Gauteng province, South Africa. South African Agric Ext. 44. 1-26, Available from: http://ref.scielo.org/ncsqcs (2016).

42. Rajaram, T., Das, A. A methodology for integrated assessment of rural linkages in a developing nation. Impact Assess Proj Apprais. 26. 99-113, (2008).

43. Atkinson, P. Using statistics to understand the environment. Vol. 25, Progress in Physical Geography. London and New York: Routredge, Tailor and Francis; (2001).

44. Cox, A.J., Sseguya, H. ICT supported extension services in conservation agriculture information access for small holder farmers in Laikipia County, Kenya. In: International Symposium on Technology and Society, Proceedings. (2016).

45. Zewdu, G.A., Malek, M. Implications of Land Policies for Rural-urban Linkages and Rural Transformation in Ethiopia. ESSP II Work Pap.15, (2010).

46. Nepoklonov, V., Maximova, M., Sukharev-Krylov, I. Monitoring of spatial data coordinate basis integrity using coordinate transformations. E3S Web Conf. 310, (2021).

47. Chandra, A., Jain, S., Qadeer, M.A. GPS locator: An application for location tracking and sharing using GPS for Java enabled handhelds. Proc - 2011 Int Conf Comput Intell Commun Syst CICN 2011. 40610, (2011).

48. Windarni, V.A., Sediyono, E., Setiawan, A. Using GPS and Google maps for mapping digital land certificates. 2016 Int Conf Informatics Comput ICIC 2016. 422-6, (2017).

\section{Figures}




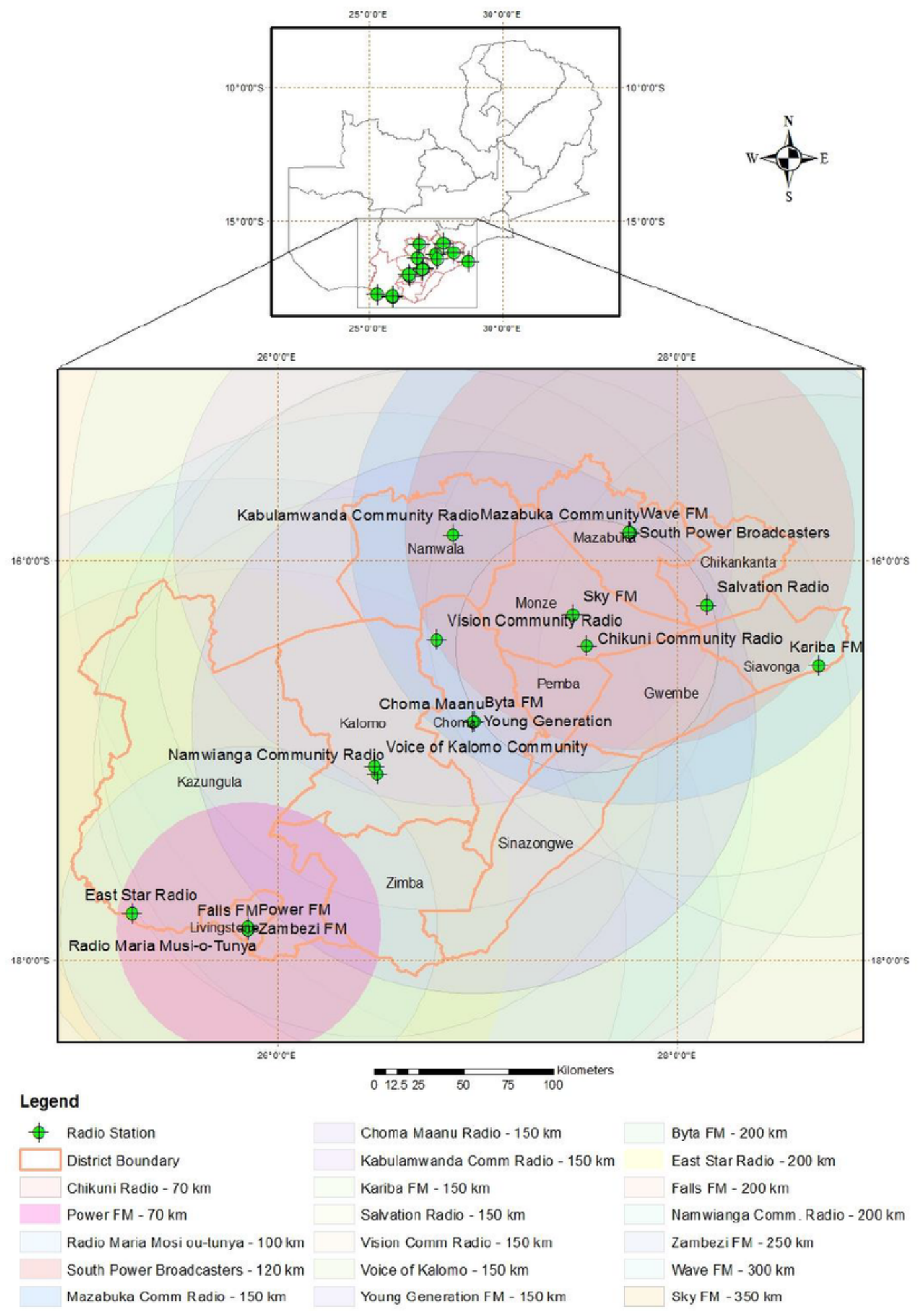

\section{Figure 1}

The Mapped CRS and their transmitter radius coverage. Source: Survey (2021) 


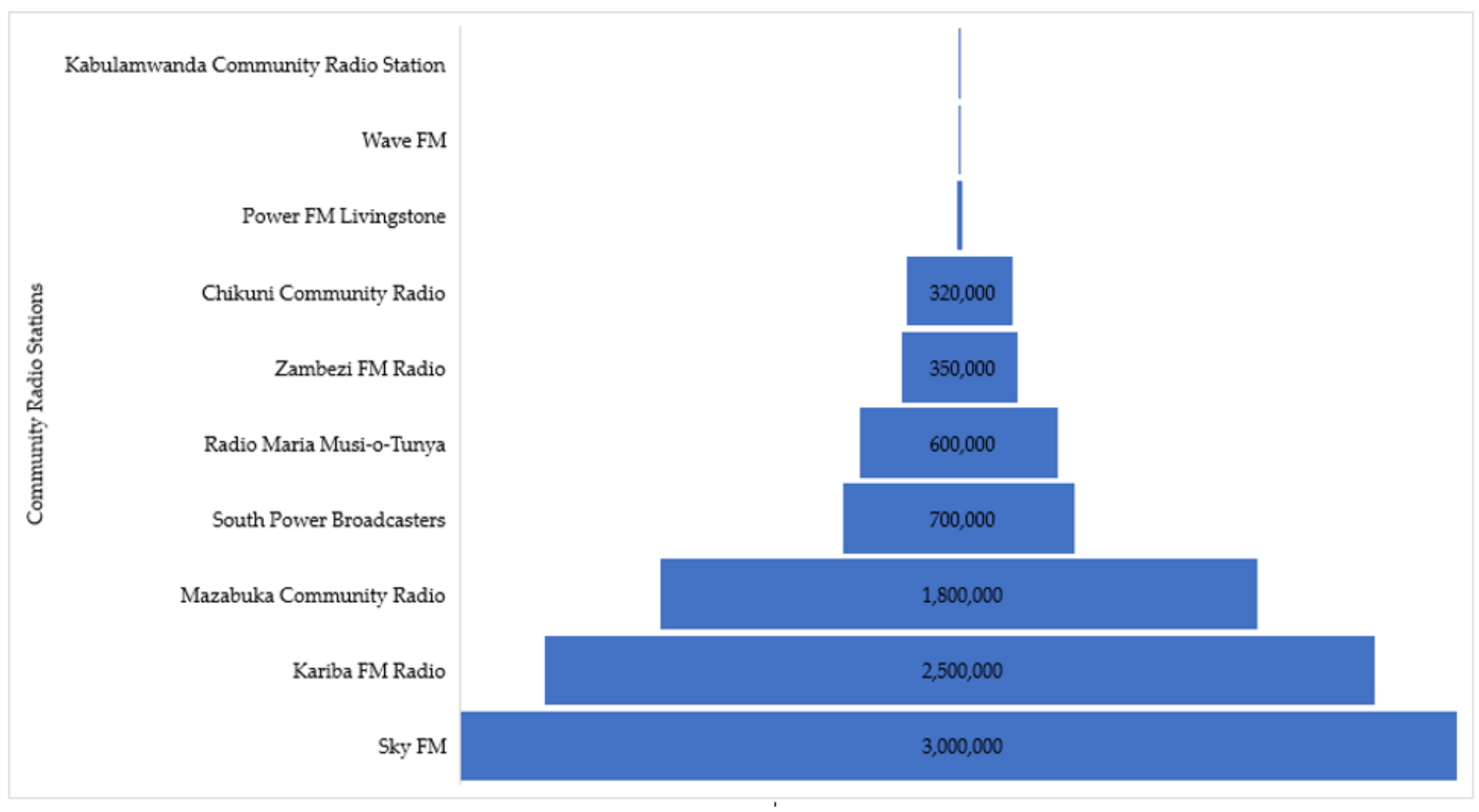

\section{Figure 2}

The estimated community radio stations listenership $(n=10)$. Source: Survey (2021) 

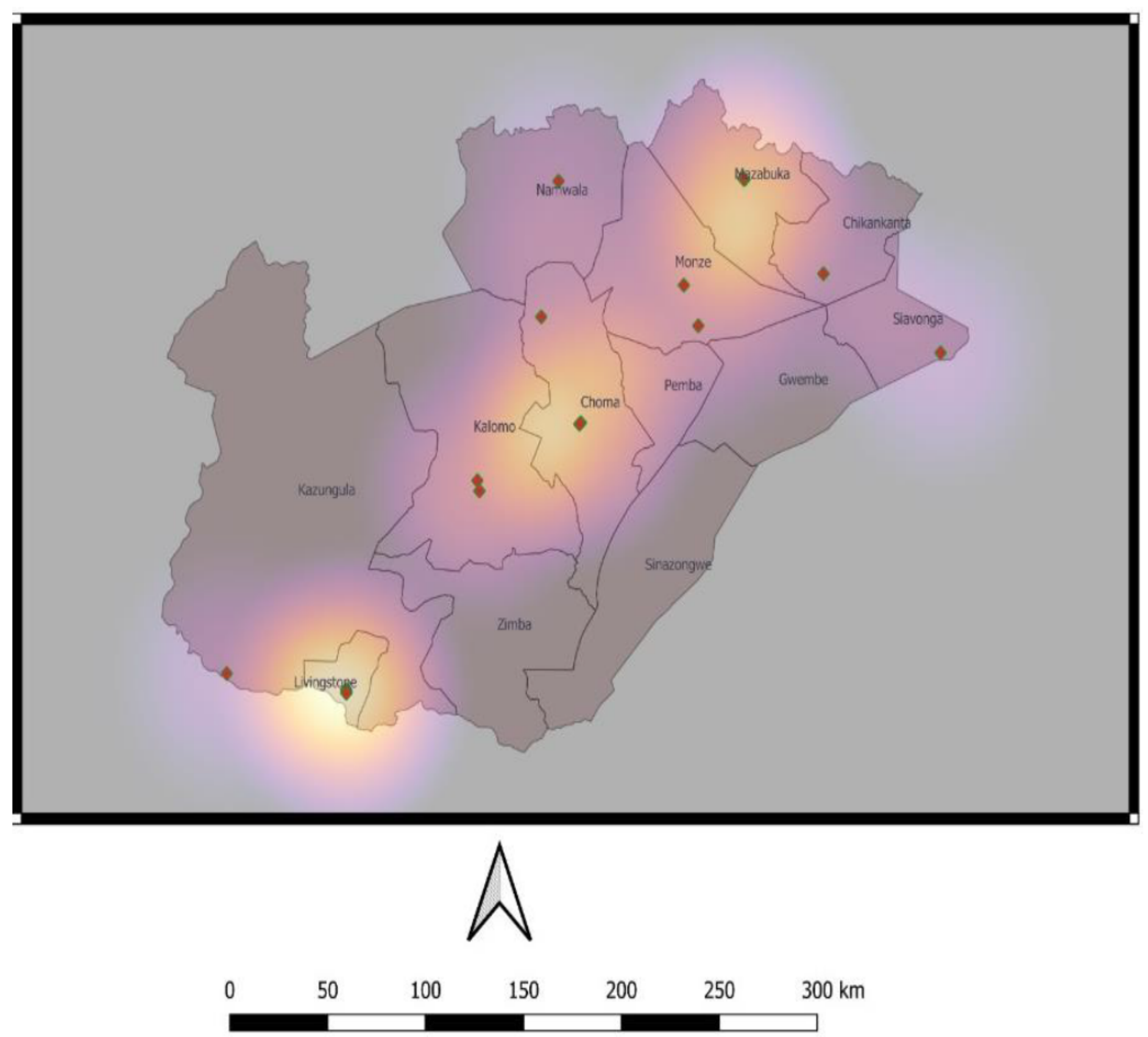

Figure 3

The heatmap based on GPS locations of CRS in Southern Province of Zambia Source: Survey (2021) 


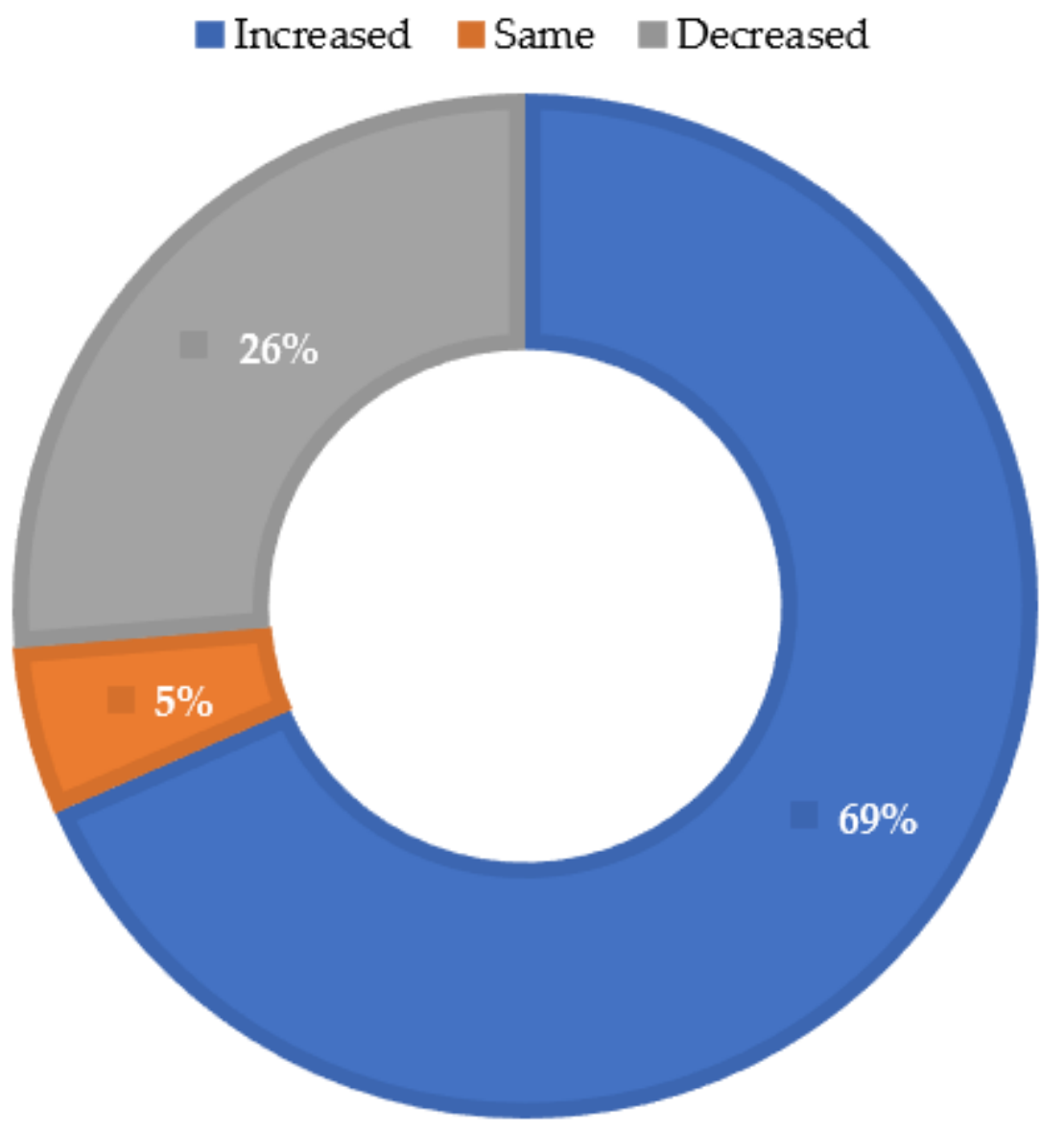

Figure 4

Demand for agricultural programs during the COVID-19 period $(n=19)$ 


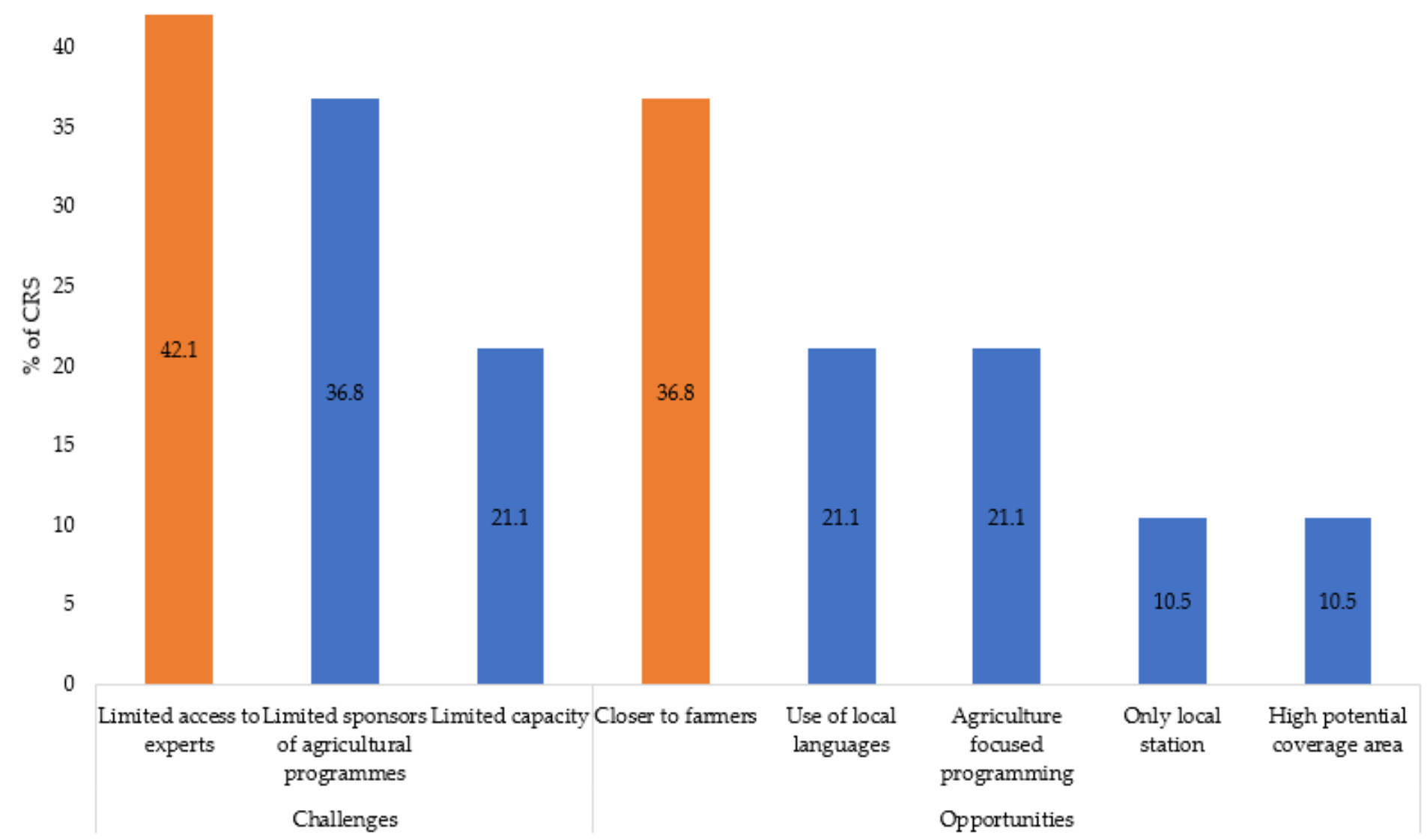

\section{Figure 5}

The challenges and opportunities for the CRS in disseminating climate adaptation measures. Source: Survey (2021) 


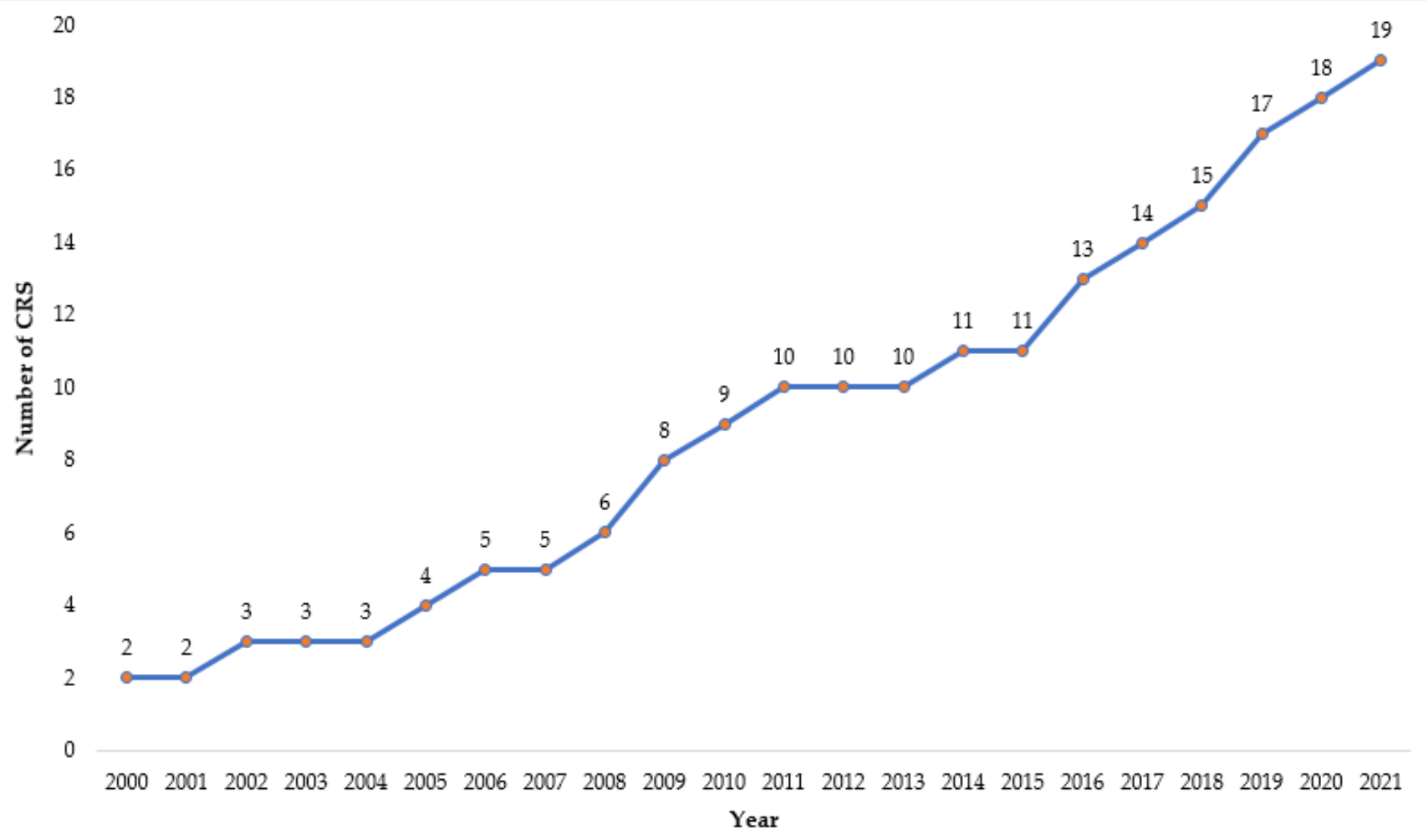

Figure 6

Cumulative registered radio stations $(n=19)$. Source: Survey (2021)

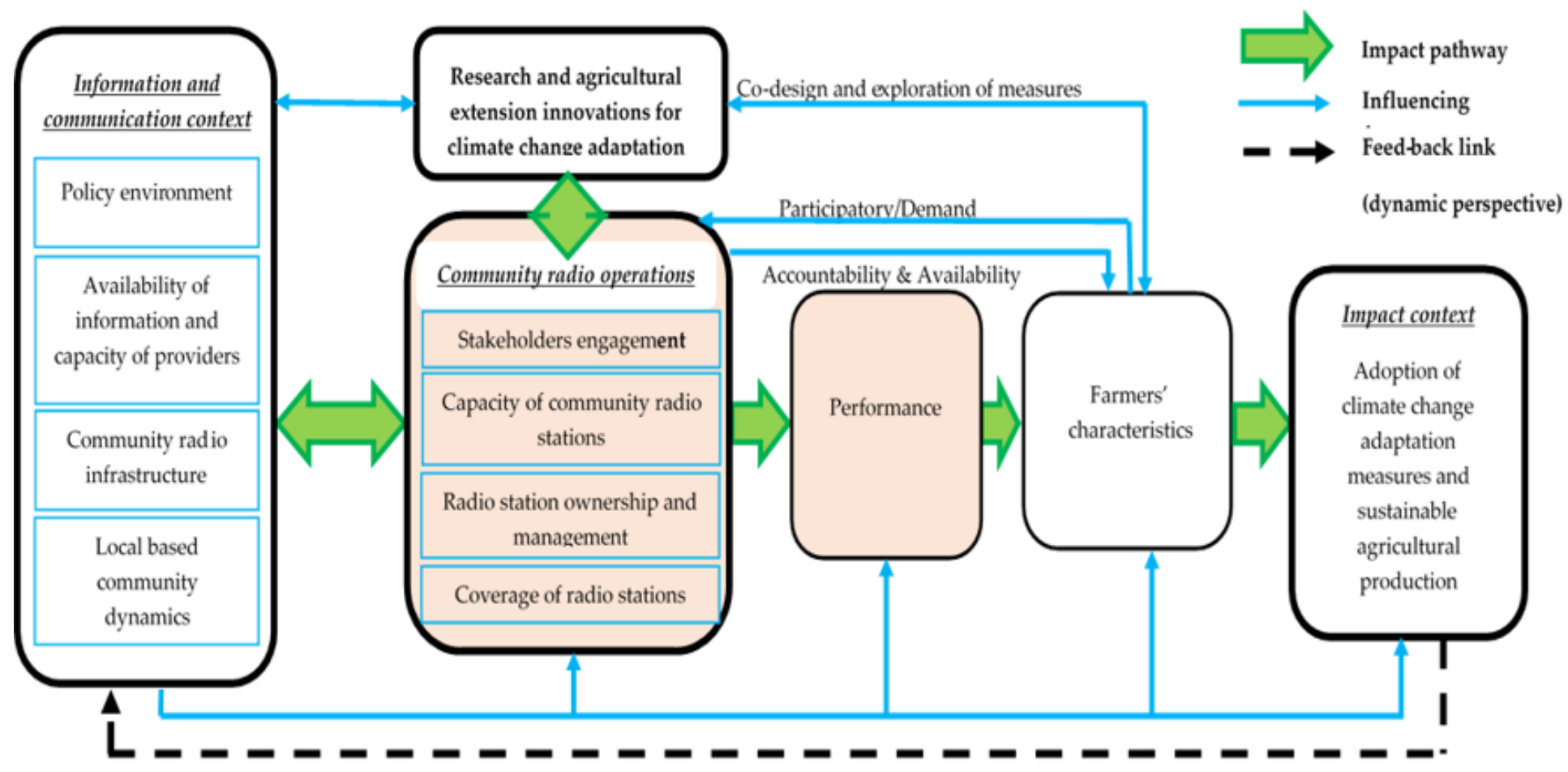




\section{Figure 7}

The conceptual framework for analyzing the potential effectiveness of CRS on the dissemination of climate change adaptation measures and sustainable agriculture. Modified from Birner et al. (2009).

\section{Objective 1. Step 1}

Collection of GPS Coordinates of radio stations and Validation of Coordinates on Google Map Platform
CSV Comma Delimited File containing GPS Coordinates of Radio Stations loaded in ArcGIS 10.3 for spatial analysis

\section{Step 2}

Radios transmission radii used to create Buffers with same spatial extent attribute in ArcGIS 10.3. Buffer layers overlaid to visualize interaction
ArcGIS Spatial Analysis products (maps, attribute tables) exported for subsequent use outside the software

\section{Objective 2 and 3 . Step 3}

Questionnaires administered to community radio station key informants
Key informants from the Ministry of Agriculture interviews to validate the information provided be community radio station key informants

\section{Figure 8}

Methodological framework. Source: Authors (2021) 


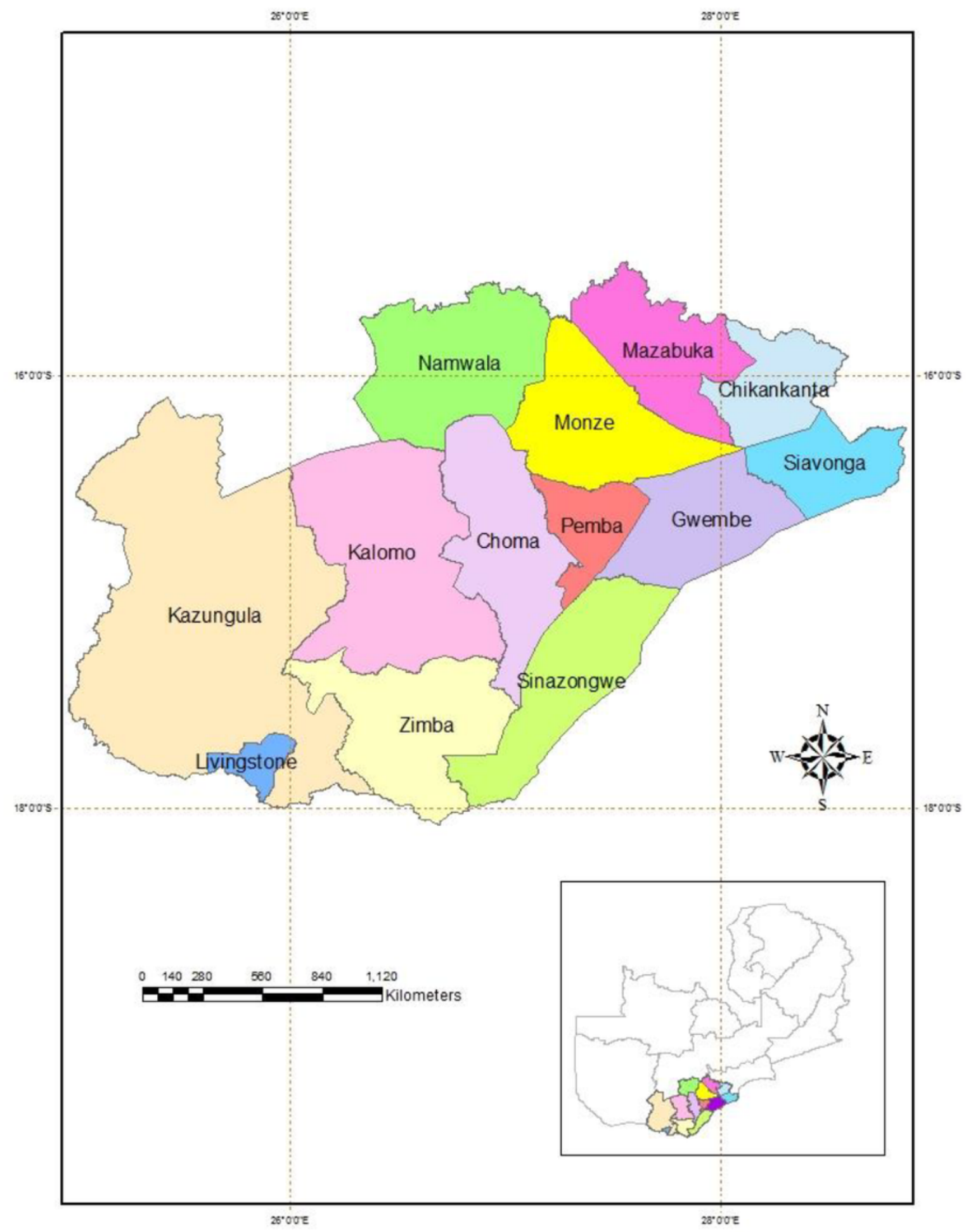

Figure 9

The Southern Province of Zambia 